\section{BOOK REVIEW}

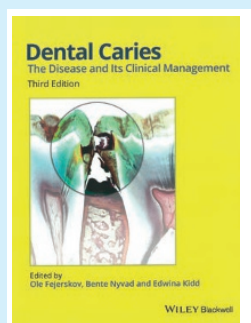

\section{DENTAL CARIES: THE DISEASE AND ITS CLINICAL MANAGEMENT, THIRD EDITION \\ Ole Fejerskov, Bente Nyvad and Edwina Kidd (Editors) \\ Wiley-Blackwell \\ price $\mathrm{f} 89.99 \mathrm{pp} 480$ \\ ISBN 978-1-118-93582-8}

Dental caries is a process which occurs on any tooth surface in the oral cavity where dental plaque is allowed to develop over a period of time. Caries is one of the main diseases treated in dentistry, with many undergraduates being able to explain a variety of treatment and prevention methods, rather than the mechanism of these and the process that led it to being required. However, with the help of this book the understanding of this disease can be vastly improved.

Now in its third edition, the book has been extensively expanded into six distinct sections - prevalence, cause, diagnosis, prevention, operative management and control. The book benefits from numerous clinical photographs and clear line drawings, which serves to illustrate the narrative well. The histology section is an excellent example of this and a good place to start for those aiming to revise their knowledge of dental hard tissues.

All aspects regarding caries are expansively covered - from the progression of a white spot lesion, both clinically and histologically, to the different fluoride modalities and their metabolism. Furthermore, the operative management is explained with a stepwise approach, with scientific studies incorporated to explain the use of different materials, for example, amalgam/ fissure sealants in both primary and permanent dentition. The book is very well referenced, which will aid readers wishing to study the topic further.

This book, which is clear and illustrated in colour, describes the causes of dental decay and its progression through the tooth in depth. Emphasis is placed upon the prevention as well as early diagnosis so that decay can be arrested in early stages. Methods of prevention from both scientific and practical aspects are covered, which makes this book ideal for undergraduate students as well as dental nurses, dental hygienists and dental therapists.

\section{Teeth Team is a real success in the North East}

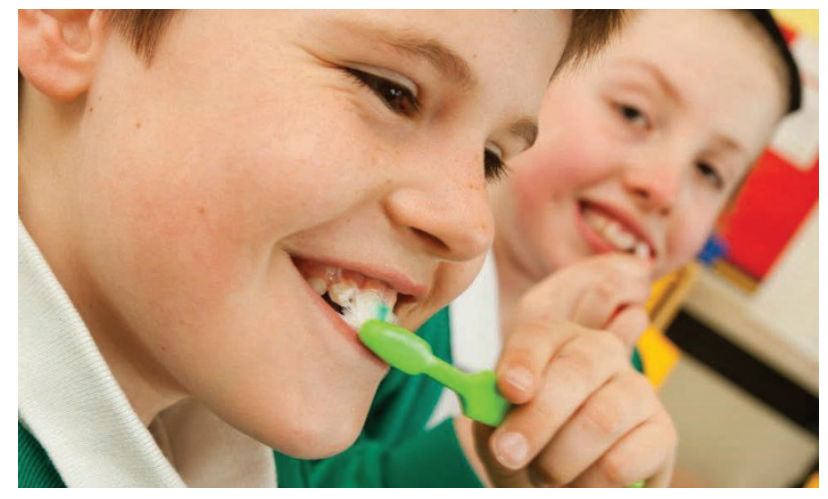

It is ten years since Ingrid Perry, a dental practice manager in Bridlington, was inspired to set up Teeth Team, a programme to raise awareness of the importance of children having access to regular dental care.

In 2006 Ms Perry visited a local primary school to deliver an oral health education session and was approached by the head teacher who expressed concerns about the number of children taking time off because of toothache. This inspired Teeth Team, which was set up in 2010.

Teeth Team currently works with more than 9,000 children across the city of Hull and East Yorkshire and is expanding into Lincolnshire. Working entirely on the efforts of volunteers and the support of businesses in the dental industry, the programme visits schools and teaches children the importance of healthy diets, effective tooth brushing and regularly attending dental checkups.

In 2012 Teeth Team launched 543junior.co.uk, an oral health education hub aimed at children aged five to 16 with games, lessons and resources for parents and teachers. Later that year they introduced fluoride varnish applications for children undergoing dental assessments as a quick and simple way of reducing the risk of tooth decay.

Since then they have received endorsements from the National Oral Health Promotion Group and the Oral Health Foundation, and have partnered with a number of businesses to take their efforts further, including Colgate, mydentist and Siemens.

Ms Perry would like to see a Teeth Team programme in every town and city in the UK and commented: 'The advice I would give to anyone who may be faltering on a project is to never give up if you truly believe in what you are trying to achieve. Sometimes it may feel like everything is against you no matter which way you turn, but if you know in your heart you can and will make a difference, then never walk away!

\title{
Easy IOTN app launched by BOS
}

The British Orthodontic Society (BOS) has launched an app called 'Easy IOTN' for dental professionals and students that aids Index of Treatment Need (IOTN) classification. The resource has been developed to help improve the standard and accuracy of orthodontic referrals as well as support and inform the training of undergraduates and foundation dentists.

The new app, named Easy IOTN, guides the user to the correct classification via the quickest possible route, using simple clinical features. Traditionally, IOTN is recognised as potentially complex which has led to it being applied incorrectly. With increased emphasis on reducing referrals for those patients who do not qualify for NHS treatment, the timing of this product launch is ideal. Also included in the app is a CPD and training section which will provide one hour of verifiable $\mathrm{CPD}$ for the user.

The app can be downloaded now for free through the Apple app store and will be available for Android phones in the New Year. 